\title{
HEMODYNAMIC EVALUATION FOR CLOSING INTERATRIAL COMMUNICATION AFTER FENESTRATED FONTAN OPERATION
}

Hideaki Senzaki, MD, Chiharu Naito, BS, Satoshi Masutani, MD, Mio Nogaki, MD, Atsuko Ohono, MD, Jun Kobayashi, MD, Nozomu Sasaki, MD, Haruhiko Asano, MD, Kyo Shunei, MD, Yuji Yokote, MD, and Toshiki Kobayashi, MD, Saitama, Japan

The fenestrated Fontan procedure has been applied to highrisk patients with univentricular hearts, ${ }^{1}$ resulting in decreased perioperative morbidity and mortality. ${ }^{2}$ The fenestration is subsequently subjected to a permanent transcatheter closure when hemodynamic responses to test occlusion are favorable. Several investigators have proposed criteria for closing fenestrations that are mainly based on the changes in central venous pressure (CVP) or cardiac output (CO) after test occlusion. ${ }^{3,4}$ Such criteria provide useful information as to whether a fenestration can be closed, and indeed, most of the patients who have undergone fenestration closure according to the criteria have a reported outcome of New York Heart Association (NYHA) class I. ${ }^{3,4}$ However, it is also true that some who did not meet the criteria but underwent fenestration closure also have a good functional class but that others who did meet the criteria have a suboptimal functional class. ${ }^{3,4}$ This evidence suggests the need for more detailed assessments to avoid such an overlap. To better understand and predict Fontan physiology after fenestration closure, we present cases that suggest the importance and usefulness of cardiac rest and reserve function assessments.

Clinical summary. We compared 2 patients who underwent fenestrated Fontan operations with subsequent fenestration closure. Characteristics for each patient are summarized in Table I, and test occlusion results are shown in Table II. Hemodynamic responses after test occlusion were quite similar between the 2 patients and almost met the aforementioned proposed criteria. However, symptoms of heart failure gradu-

From the Department of Pediatric Cardiology and Cardiovascular Surgery, Saitama Medical School Hospital, Saitama, Japan.

J Thorac Cardiovasc Surg 2001;121;1200-2

Copyright $\odot 2001$ by The American Association for Thoracic Surgery

0022-5223/2001 $\$ 35.00+0 \quad \mathbf{1 2 / 5 4 / 1 1 1 3 7 6}$

doi: $10.1067 / \mathrm{mtc} .2001 .111376$ ally developed in patient A after the fenestration closure, including hepatomegaly, edema (particularly after mild exercise), and fatigability (classified as NYHA class III). In contrast, patient B has been in NYHA class I for 3 years after fenestration closure. Follow-up cardiac catheterization was performed 7 and 13 months after the fenestration closure for each patient and revealed no anatomic obstruction or stenosis, valvular regurgitation, or aortopulmonary collateral vessels. Hemodynamic data are shown in Table III. Systolic and diastolic function indicated by conventional indexes and pulmonary artery resistance were similar between the 2 patients and thus failed to differentiate between the functional status of the 2 patients. However, a load-independent contractility index, end-systolic elastance (Ees), ${ }^{5}$ measured by means of pressure-area analysis during transient caval occlusion, was markedly lower in patient $\mathrm{A}$ than in patient $\mathrm{B}$, suggesting impaired ventricular contractility in patient A. Furthermore, responses to increased heart rate (HR) and to $\beta$-adrenergic stimulation revealed marked disparity in cardiac reserve function between the 2 patients. Fig 1, A, displays the hemodynamic responses to increased HR by atrial pacing, with data shown as percentage changes from baseline values. Although ventricular contractility (Ees) increased with increased HR in patient $\mathrm{B}$, this positive force-frequency response was significantly diminished in patient A. Diastolic function (relaxation time constant) improved as HR increased in patient B but not in patient A. Pacing reduced ventricular preload (end-diastolic area) in both patients but more so in patient $\mathrm{A}$, together with a marked increase in pulmonary capillary wedge pressure suggestive of limited ventricular filling at higher HRs in patient A. Consequently, increased HR resulted in an increase in $\mathrm{CO}$ and a minimal increase in CVP in patient $\mathrm{B}$, whereas $\mathrm{CO}$ decreased and CVP markedly increased in patient A. Fig $1, B$, displays pressure-area relations before and after dobutamine infusion $\left(15 \mu \mathrm{g} \mathrm{kg}^{-1} \mathrm{~min}^{-1}\right)$. The slope of end-systolic pressure-area relation (Ees) markedly increased with dobutamine administration in patient $\mathrm{B}$. In contrast, patient $\mathrm{A}$

Table I. Patient characteristics

\begin{tabular}{|c|c|c|}
\hline & Patient A & Patient $B$ \\
\hline Sex & Female & Male \\
\hline Diagnosis & $\begin{array}{l}\text { Taussig-Bing anomaly, coarctation of aorta, } \\
\text { subaortic stenosis, single right coronary artery }\end{array}$ & Hypoplastic right ventricle, VSD, TGA, PS \\
\hline Palliative operation (age at operation) & Pulmonary artery banding with coarctectomy (7 d) & BTS (1 mo), bidirectional Glenn (5 y) \\
\hline Fontan procedure (age at operation) & TCPC with baffled lateral tunnel, Damus-Kaye-Stansel (3 y) & TCPC with baffled lateral tunnel (6 y) \\
\hline Age at final catheterization $(y)$ & 7 & 10 \\
\hline
\end{tabular}

$V S D$, Ventricular septal defect; $T G A$, transposition of the great arteries; $P S$, pulmonary stenosis; $B T S$, Blalock-Taussig shunt; $T C P C$, total cavopulmonary connection. 


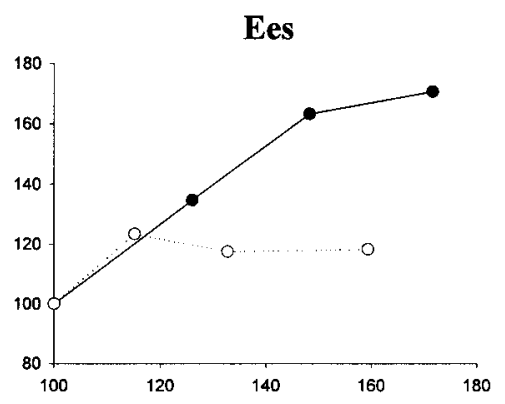

Tau
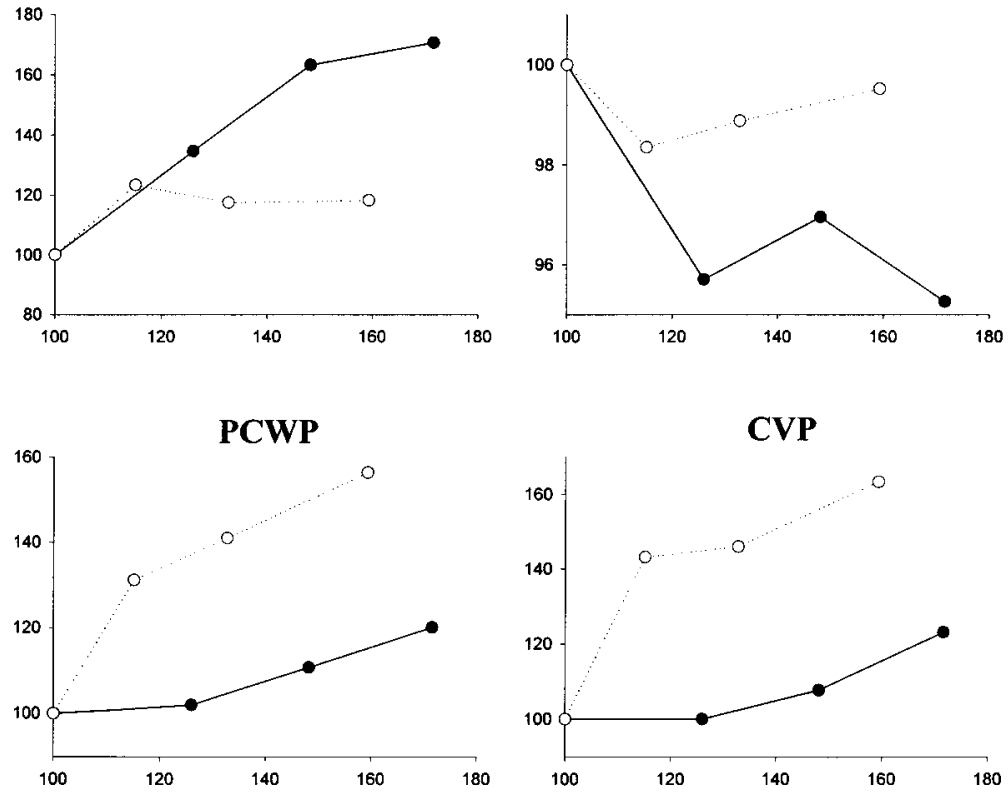

CVP
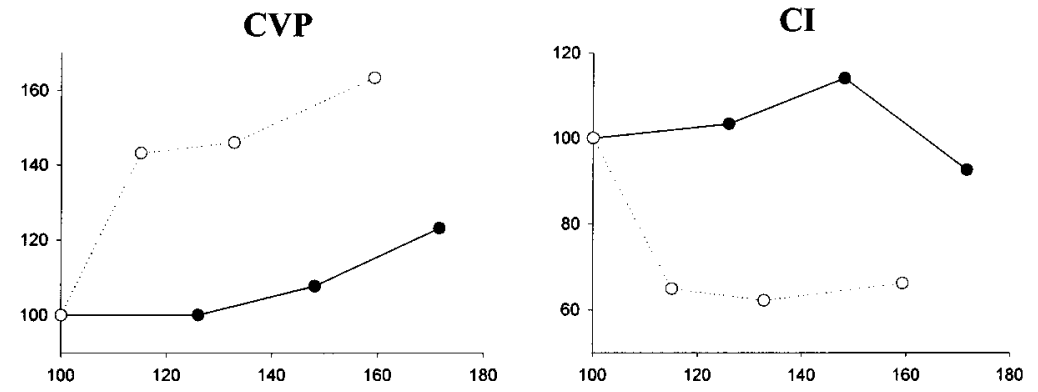

A $\%$ change in HR

Patient A

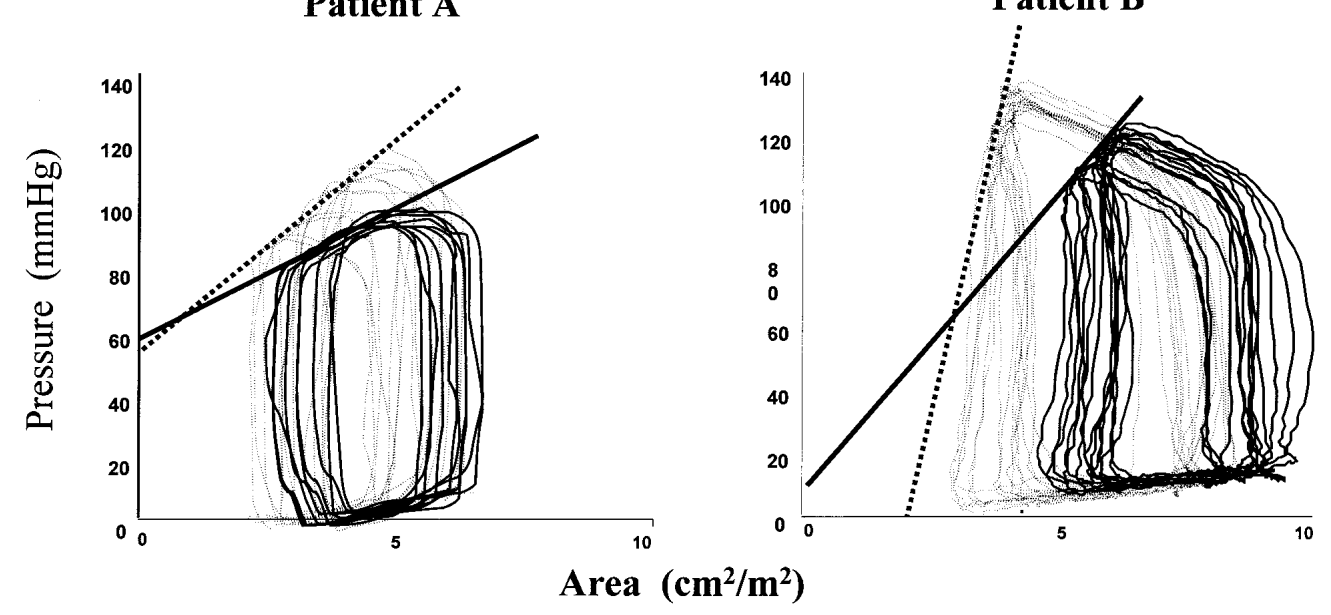

B
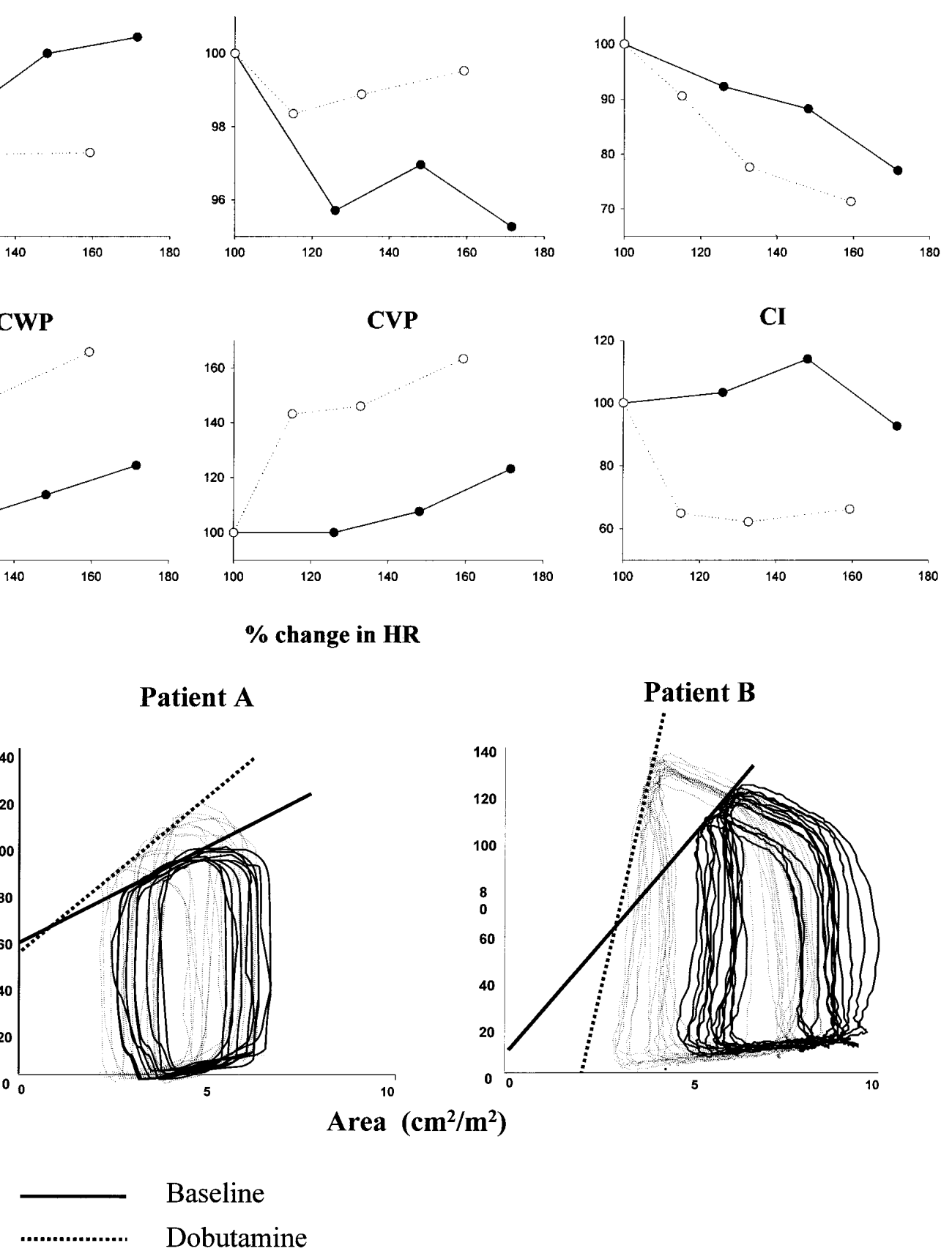

CI 
Table II. Hemodynamic response to test occlusion

\begin{tabular}{|c|c|c|c|c|}
\hline & \multicolumn{2}{|c|}{ Patient A } & \multicolumn{2}{|c|}{ Patient B } \\
\hline & Before occlusion & After occlusion & Before occlusion & After occlusion \\
\hline $\mathrm{SaO}_{2}(\%)$ & 89 & 93 & 90 & 94 \\
\hline $\mathrm{SVO}_{2}(\%)$ & 67 & 60 & 65 & 59 \\
\hline$\Delta\left(\mathrm{A}-\mathrm{V} \mathrm{O}_{2}\right)(\%)$ & 22 & 33 & 25 & 35 \\
\hline CVP (mm Hg) & 11 & 12 & 12 & 14 \\
\hline $\mathrm{CI}\left(\mathrm{L} \cdot \mathrm{min}^{-1} \cdot \mathrm{m}^{-2}\right)$ & 3.1 & 2.7 & 3.3 & 2.9 \\
\hline
\end{tabular}

$\mathrm{SaO}_{2}$, Arterial oxygen saturation; $\mathrm{SVO}_{2}$, mixed venous oxygen saturation; $\Delta\left(\mathrm{A}-\mathrm{VO}_{2}\right)$, arteriovenous difference in oxygen saturation; $\mathrm{CI}$, cardiac index.

Table III. Baseline hemodynamics at the final catheterization after fenestration closure

\begin{tabular}{lcc}
\hline & Patient $A$ & Patient $B$ \\
\hline $\mathrm{HR}($ beats/min $)$ & 96 & 81 \\
$\mathrm{SaO}_{2}(\%)$ & 94 & 94 \\
$\mathrm{Rp}\left(\mathrm{RUm}{ }^{2}\right)$ & 1.9 & 2.6 \\
$\mathrm{CVP}(\mathrm{mm} \mathrm{Hg})$ & 11 & 13 \\
$\mathrm{EF}(\%)$ & 48 & 50 \\
$\mathrm{dp} / \mathrm{dt}$ max & 1156 & 1250 \\
$\tau(\mathrm{ms})$ & 43 & 47 \\
$\mathrm{EDA}\left(\mathrm{cm}^{2} / \mathrm{m}^{2}\right)$ & 7 & 10 \\
$\mathrm{EDP}(\mathrm{mm} \mathrm{Hg})$ & 5 & 6 \\
Ees $\left(\mathrm{mm} \mathrm{Hg} \cdot \mathrm{cm}^{2} / \mathrm{m}^{2}\right)$ & 10 & 19
\end{tabular}

$\mathrm{SaO}_{2}$, Arterial oxygen saturation; $R p$, pulmonary vascular resistance; $E F$, ejection fraction; $\tau$, relaxation time constant; $E D A$, end-diastolic area; $E D P$, enddiastolic pressure.

sure-area analysis clearly contrasted the difference between the 2 patients.

Because there is no ventricle propelling venous flow into a single ventricle in Fontan physiology, ventricular preload reserve is inevitably limited in this circulation. Conventional indexes for ventricular systolic-diastolic function are load dependent and generally more evident as load increases. ${ }^{5}$ Thus, limited preload reserve in the Fontan circulation is inherently prone to mask the ventricular dysfunction when assessed by means of such indexes. The loadindependent measure of ventricular function provided by pressure-area analysis is therefore highly beneficial in this setting. In addition, the limited preload reserve would become more crucial when ventricular filling time is shortened, as occurs with rapid HR. Ventricular diastolic dysfunction would further exacerbate filling disturbance in this condition. Thus, hemodynamic evaluation in response to increased HR can be useful in the unmasking of ventricular dysfunction in patients with Fontan circulation. Last, diminished $\beta$-adrenergic reserve is commonly observed in heart failure and is closely related to the decreased exercise capacity of patients undergoing heart failure. The maintenance of cardiac output by the adrenergic reserve would increase in importance under the condition of limited cardiac filling in the Fontan circulation.

In summary, pressure-area analysis at rest and responses to increased HR by means of atrial pacing and to $\beta$-adrenergic stimulation could provide more detailed information about Fontan physiology. These may be useful in determining whether to close the fenestration, particularly when responses to test occlusion are borderline.

Received for publication Aug 23, 2000; accepted for publication Sept 1, 2000.

Address for reprints: Hideaki Senzaki, MD, Department of Pediatric Cardiology, Saitama Heart Institutes, Saitama Medical School Hospital, 38 Morohongo, Moroyama, IrumaGun, Saitama, 350 Japan (E-mail: hsenzaki@saitamamed.ac.jp).

\section{REFERENCES}

1. Bridge ND, Lock JE, Castaneda AR. Baffle fenestration with subsequent transcatheter closure: modification of the Fontan operation for patients at increased risk. Circulation 1990;82:1681-9

2. Gentle TL, Mayer JE Jr, Gauvreau K, Newburger JW, Lock JE, Kupferschmid JP, et al. Fontan operation in five hundred consecutive patients: factors influencing early and late outcome. J Thorac Cardiovasc Surg 1997;114:376-91.

3. Bridge ND, Lock JE, Jonas RA, Mayer JE Jr, Burnett J, Castaneda AR. Cardiac catheterization and test occlusion of the interatrial communication after the fenestrated Fontan operation. J Am Coll Cardiol 1995;25:1712-7.

4. Marvroudis C, Zales VR, Backer CL, Muster AJ, Latson LA. Fenestrated Fontan with delayed catheter closure: effects of volume loading and baffle fenestration on cardiac index and oxygen delivery. Circulation 1992;86(Suppl):II-85-92.

5. Kass DA, Maughan WL, Gui AM, Kono A, Sunagawa K, Sagawa K. Comparative influence of load versus inotropic states on indexes of ventricular contractility: experimental and theoretical analysis based on pressure-volume relationships. Circulation 1987;76:1422-36. 